\title{
Comprehensive Power Transformers Evaluation based on Multi-Criteria Decision-Making Approach
}

\author{
Stojan VASOVIĆ, Aleksandar DRAGAŠEVIĆ, Slaviša PUZOVIĆ, Sanja PUZOVIĆ*, Vladan PAUNOVIĆ
}

\begin{abstract}
Selection of adequate power transformers is among the most important factors for ensuring well-operated and optimized power generation and distribution systems, which imposes the need for applying optimization methods in order to obtain comprehensive evaluation process. In the paper, a multi-criteria group decision-making supportive model for the power transformer evaluation is proposed; the model is based on integration of the Analytic Hierarchy Process (AHP) and the compromise ranking method with fuzzy Set Theory. The AHP method was utilized in order to estimate the criteria relative weights, whereas the compromise ranking method was used for alternative assessment and compromise ranking. Integration of the fuzzy logic within the proposed model allows dealing with problem of the ambiguities of human perceptions and provides more rational results. A numerical example illustrates the proposed methodology on the real MCDM problem of power transformers selection.
\end{abstract}

Keywords: AHP; compromise ranking method; fuzzy Set Theory; MCDM; power transformers evaluation

\section{INTRODUCTION}

Power transformers are among the most important equipment in electrical power transmission and distribution systems, and the occurrence of any fault in these transformers will reduce the power system reliability [1]. It may also lead to a loss of power in parts of the system, which can be costly and inconvenient for customers [2]. In addition, it will impose extra maintenance costs.

The efficient transmission process is one of the most important factors for ensuring well-operated and optimized power generation and distribution systems. In other words, it implies the use of safely-operated and remarkably performing power transformers, which will ensure a long lifetime with constant reliability; environment-friendly influences; acceptable purchase and installation costs; low no-load/load losses so as to ensure cost savings.

Due to the fact that an improper power transformer selection may negatively affect the overall performance and productivity of these systems, it is essential that a deep analysis should be carried out, taking into account all the indispensable aspects of evaluation. These aspects might be categorized into two conflicting groups, namely costs and technical characteristics, which makes the selection process even more complex. All this makes power transformer selection a multicriteria optimization problem. Since such a selection procedure is unstructured and characterized by extensive domain-dependent knowledge, the application of an effective and efficient MCDM tool is required [3]. Essentially, power transformer selection problem solving has to rely on the application of the hybrid MCDM models that will be able to provide consistent criteria relative weights and also successfully deal with the complexity of the process of the assessment of alternatives, taking into consideration different aspects of evaluation.

In addition, due to conflicting and incommensurate evaluation criteria and vague data, the power transformer evaluation process also includes a lot of uncertainties which can make this process complicated for decisionmakers. This requires the integration of fuzzy set theory in MCDM models due to its ability to deal with uncertainty and vagueness inherent to this process.

Different hybrid MCDM methods are introduced in order to find a solution to the problems of the evaluation of the equipment of different purposes and features. Reference [4] compares three MCDM methods for the solving the problem of equipment selection in the early stages of the chemical manufacturing process, those methods being the AHP, Multi-Attribute Range Evaluations (MARE) and ELimination Et Choix Traduisant la REalité trois (ELECTRE III). The study [5] proposes an integrated approach to the evaluation of the occupational safety equipment based on two MCDM methods, the AHP method and the fuzzy Preference Ranking Organization Method for Enrichment Evaluation (PROMETHEE) are employed in order to successfully deal with the complexity of the evaluation process.

In the reference [6], a new hybrid MCDM model is proposed so as to deal with the process of the evaluation of construction equipment under a fuzzy environment. The model is based on the fuzzy extensions of the Step-wise Weight Assessment Ratio Analysis (SWARA) and the CRiteria Importance through Intercriteria Correlation (CRITIC) methods for determining the subjective and the objective weights of criteria, and the fuzzy Evaluation based on Distance from Average Solution (EDAS) method for evaluating alternative.

The authors Yilmaz and Dağdeviren [7] introduced an approach for the selection of the most suitable equipment, including both the fuzzy PROMETHEE and the 0-1 goal programming methods. The vagueness of the linguistic terms in the evaluation process concerning the problem of the selection of a machine is handled applying fuzzy logic within the PROMETHE process. The results obtained by the fuzzy PROMETHEE method are further used as a constraint in formulating the zero-one goal programming model.

Hadi-Vencheh and Mohamadghasemi [8] introduced a framework for the selection of the optimal materialhandling equipment, within which the fuzzy Weighted Average (FWA) is utilized in order to aggregate the single fuzzy weights of each alternative related to the sub-criteria under each criterion, and the fuzzy compromise ranking method is used to select the optimal equipment. Also, in order to demonstrate the effectiveness of the proposed approach, the authors compared the obtained results with the results obtained by the fuzzy Technique for Order Preference by Similarity to Ideal Solution (TOPSIS) method. Yazdani-Chamzini [9] proposed the equipment 
evaluation model derived from group decision-making, the fuzzy Set theory, and the two MCDM methods: the AHP, for calculating the relative importance of the evaluation criteria, and TOPSIS, for evaluating the equipment.

In the reference [10], an approach employing the Simple Additive Weight (SAW) and the compromise ranking methods is proposed for the purpose of analyzing the structure of the equipment selection problem, determining the weights of criteria and obtaining final rank.

The overall objective of this study is to establish and verify the methodological framework for the evaluation and selection of power transformers, which may affect ensuring well-operated and optimized power generation and distribution systems. Namely, the paper is aimed at establishing the model that leads to the systematic concept for the comprehensive evaluation of power transformers under fuzzy environment. The fuzzy compromise ranking method is an integral part of this model and is employed in order to successfully deal with the complexity of the power transformer evaluation process under fuzzy environment by obtaining the compromise ranking of the alternative based on proximity to the ideal solution, thus providing a compromise solution according to the decision-maker's preferences.

In addition, the paper is aimed at providing the structured approach that can make it easier for decisionmakers to identify and assess the relative importance among the various elements and factors influencing power transformer selection decisions.

One of the objectives of the paper is to propose comprehensive criteria for the evaluation of power transformers, including a set of different indicators and a combination of both qualitative and quantitative evaluation criteria. Although a multiple-criteria evaluation can provide consistent alternative ratings, the major issue with such an evaluation is which priority different criteria should be considered so as to enable that the decisionmaker's preferences are reflected in a right way. The key issue the criteria prioritization process is accompanied by includes many uncertainties caused by the inconsistency of the decision-maker's opinions, the impossibility of expressing preferences relations by means of crisp measures, incomplete information, the vagueness of human perception and a lack of quantitative measures. The model proposed in this paper is aimed at responding to those challenges as well. It is based on the extension of the Analytic Hierarchy Process for dealing with the fuzzy problems of prioritizing power transformer evaluation criteria in the fuzzy set context.

In the literature, there are various examples of the utilization of the AHP-compromise ranking hybrid model under a fuzzy environment for problem solving in diverse fields. In the study [11], this model was used for the purpose of the evaluation of the gradual process of Product Lifecycle Management (PLM) maturity in order to build the internal logical relationship between the maturity levels and the existing values that can automatically predict the unknown PLM maturity levels. The same model was applied for the purpose of the multi-tier sustainable global supplier selection [12] and for the evaluation and selection of urban planning projects [13]. A group of authors introduced the model for the selection of a sustainable manufacturing strategy with the integrated AHP and compromise ranking method under an interval-valued fuzzy environment [14], whereas the paper [15] is aimed at performing a benchmarking analysis in the hotel industry by using the fuzzy AHP-compromise ranking method hybrid model, too. Gul [16] proposed the Pythagorean fuzzy AHP and compromise ranking methods for the assessment of the risk of occupational health and safety. The authors Jamali and Khamene [17] presented a strategic management method for measuring the performance of the aircraft maintenance unit by using a set of financial and non-financial performance metrics and the fuzzy AHPcocompromise ranking method promise ranking based approach.

Although fuzzy MCDM-based models are often used in the literature on equipment evaluation, there is a noticeable lack of the studies that consider the problem of power transformer selection as a fuzzy MCDM problem. Unlike previous studies, this paper offers a systematic concept for comprehensive power transformer evaluation in a fuzzy environment, based on a set of different indicators and a combination of both qualitative and quantitative evaluation criteria.

The literature notes the frequent use of the fuzzy extension of the AHP method in criteria prioritization, which is presented above. However, unlike the identified fuzzy AHP models used for equipment selection, a fuzzy synthetic extent analysis is employed in this paper, with the help of which synthetic range values for each considered attribute are obtained from a fuzzy pairwise comparison matrix, based on which a criteria weight vector is obtained. This provides a more sensible prioritization of the evaluation criteria and the successful capturing of the uncertainties inherent to this process.

In order to demonstrate the effectiveness of the proposed approach, the power transformers selection process was implemented in an electricity distribution company. The subject of analysis in this paper will be four different types of power transformers from different manufacturers, i.e. dry-type transformers in two variants (with and without reduced losses) and liquid-filled transformers, also in two variants (with and without reduced losses). The different technical features of these transformers may have different implications on performances of distribution systems.

The dry-type and liquid-filled transformers are predominantly present in Serbia's distribution system, covering over $97 \%$ of the total number of transformers in the field of the power distribution system in Serbia.

The company aim was to select optimal power transformer in relevance to such targets as: ensuring safe operation and remarkable performance that will ensure long lifetime with constant reliability; environmentfriendly influences; an acceptable purchase and installation cost; low no-load/load losses so as to ensure cost reducing.

\section{THE PROPOSED METHODOLOGY}

The proposed framework (Fig. 1) is aimed to establishing a systematic power transformers evaluation process, integrating fuzzy AHP method with fuzzy compromise ranking method. 


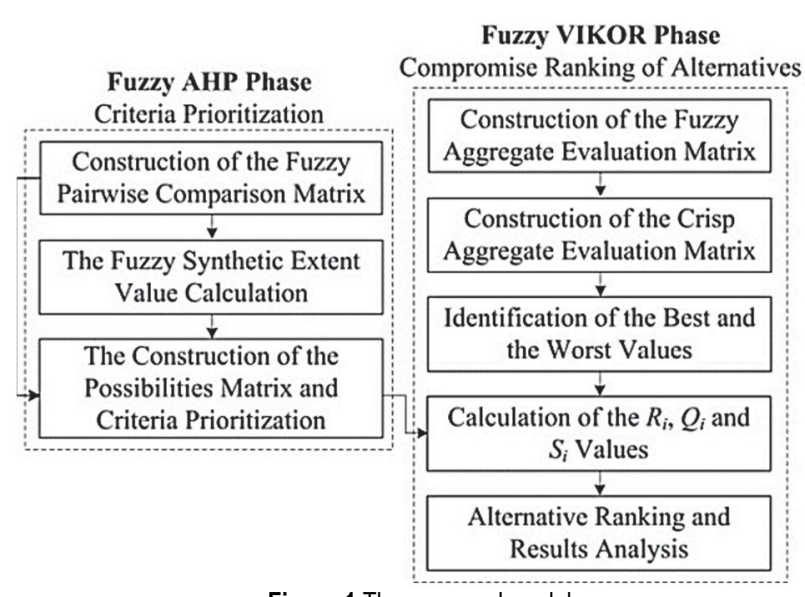

Figure 1 The proposed model

\subsection{The Fuzzy AHP Method}

The AHP was introduced by Saaty [18] for solving complex multi-criteria decision-making problems. It provides a methodology for structuring the complex problems involving more than one criterion into the hierarchy of the decision-making levels (the goal, the criteria, and the alternative) and for prioritizing each hierarchy level by using a pairwise comparison. This method also enables the estimation whether there is contradiction between the subjective judgments of a problem, which is an effective way to describe the decision maker's judgment objectively. [19]

Apart from its simplicity, the conventional AHP method shows certain weaknesses, which limit its application in situations when there is any indefiniteness whatsoever in the data about the problem that is being considered [20], also it cannot reflect the human way of thinking due to the imprecision and vagueness of human perceptions. In order to rationalize the uncertainty accompanying the decision-making process, it is necessary that new approaches to dealing with uncertainty within the conventional AHP process, such as fuzzy Set Theory, should be incorporated. Fuzzy logic provides a more realistic way for dealing with undetermined human judgments [21], this theory is oriented towards the conversion of human perceptions, such as linguistic statements, into an arithmetical form by representing vague data by using fuzzy numbers [22].

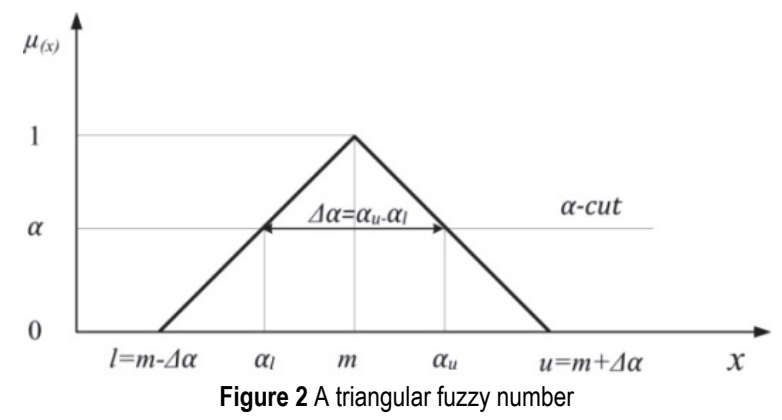

Triangular fuzzy Numbers (TFN) are most often used to describe fuzzy events. The TFN (Fig. 2) is characterized by the three real numbers expressed as a triple $(l, m, u)$, where $l \leq m \leq u$.

The criteria prioritizing process begins with the construction of a fuzzy pairwise comparison matrix
$A=\left\{a_{i j}\right\}_{n \times m}$ (1), where $a_{i j}$ represents the preference of the criterion $i$ over the criterion $j$.

$$
A_{i j}=\left|\begin{array}{cccc}
1 & a_{12} & \ldots & a_{1 m} \\
a_{21} & 1 & \ldots & a_{2 m} \\
\ldots & \ldots & \ldots & \ldots \\
a_{n 1} & a_{n 2} & \ldots & a_{n m}
\end{array}\right|
$$

Since it is very difficult for conventional quantification to express the relations that are complex or hard to define, such as those preferences relations, it is necessary to introduce language expressions for describing such situations. Therefore, those preferences relations are expressed as language statements: Equally important, Weakly more important, Strongly more important... In order to successfully deal with the imprecise or vague nature of linguistic assessments, such assessments will be quantified by TFNs. The triangular membership function which characterizes each TFN $(l, m, u)$ shown in Eq. (2), enables the mapping of linguistic statements to a closed interval $[0,1]$. Fuzzification within the criteria prioritization process in this paper will be performed according to the preferences scale demonstrated in Tab. 1.

$\mu_{M}(x)= \begin{cases}\frac{x-l}{m-l}, & x \in[l, m], \\ \frac{x-u}{m-u}, & x \in[l, m] \\ 0, & \text { otherwise }\end{cases}$

Table 1 The fuzzified criteria evaluation scale [22]

\begin{tabular}{|l|c|}
\hline \multicolumn{1}{|c|}{ Linguistic statements } & Corresponding fuzzy number \\
\hline Equally important & $(1 ; 1 ; 1)$ \\
\hline Weakly important & $(2 ; 3 ; 4)$ \\
\hline Essentially important & $(4 ; 5 ; 6)$ \\
\hline Very strongly important & $(6 ; 7 ; 8)$ \\
\hline Absolutely important & $(7 ; 8 ; 9)$ \\
\hline Intermediate values (' $x)$ & $(x-1 ; x ; x+1)$ \\
\hline Between two adjacent judgments & $(1 / x-1 ; 1 / x ; 1 / x+1)$ \\
\hline
\end{tabular}

In order to establish a group decision-making system and collect the opinions of the group of the experts involved in the pairwise comparison process, their individual judgments might be aggregated by using the fuzzy geometric mean method (3).

$M=\left(\Pi_{i=1}^{k} a_{i j k}\right)^{\frac{1}{n}}=\left\{a_{i j}\right\}$

where: $a_{i j k}$ is the $k^{\text {th }}$ expert's judgment; $n$ - the total number of the experts involved in the pairwise comparison process.

The criteria prioritization performed in this paper will be carried out by the implementation of Chang's extent analysis method [23] into the prioritization process in order to determine the relative weights by means of the synthetic extent value $(4,5)$, which can be derived from the aggregate fuzzy pairwise comparison matrix established according to (3). 
$S_{i}=\sum_{j=1}^{m} m_{i j} \otimes\left[\sum_{i=1}^{n} \sum_{j=1}^{m} m_{i j}\right]^{-1}$

$S_{i}=\left(\frac{l_{i}^{\prime}}{\sum_{i=1}^{n} u_{i}^{\prime}}, \frac{m_{i}^{\prime}}{\sum_{i=1}^{n} m_{i}^{\prime}}, \frac{u_{i}^{\prime}}{\sum_{i=1}^{n} l_{i}^{\prime}}\right)=\left(l_{i}, m_{i}, u_{i}\right)$

What follows is the determination of the minimum degree of the possibility of the superiority of one criterion over another, e.g. $\left(S_{2}=\left(l_{2}, m_{2}, u_{2}\right) \geq S_{1}=\left(l_{1}, m_{1}, u_{1}\right)\right)(6-8)$.

$V\left(S_{2} \geq S_{1}\right)=\mu_{S_{2}}(d)=\sup \left[\min \left(\mu_{S_{1}}(x), \mu_{S_{2}}(y)\right)\right]$

$\mu_{S_{2}}(d)=\left\{\begin{array}{cc}1, & \text { if } m_{2} \geq m_{1} \\ 0, & \text { if } l_{1} \geq u_{2} \\ \frac{l_{1}-u_{2}}{\left(m_{2}-u_{2}\right)-\left(m_{1}-l_{1}\right)} & \text { otherwise }\end{array}\right.$

$V\left(S_{2} \geq S_{1}\right)=\operatorname{hgt}\left(S_{1} \cap S_{2}\right)=\mu_{S_{1}}(d)$

This can be interpreted as is shown in Fig. 3.

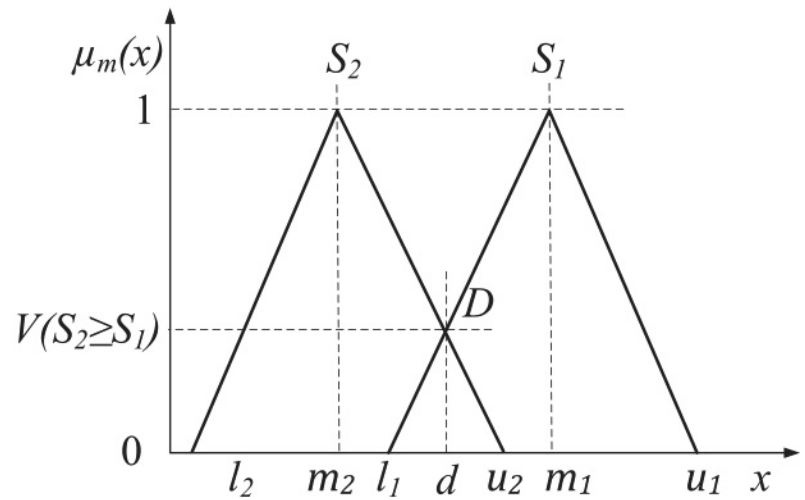

Figure 3 The intersection between $S_{1}$ and $S_{2}$ and their degree of possibility [22]

The rest will be found in the same way.

Based on the calculated preference of $S_{i}$ and $S_{k}$, the degree of the possibility for a convex fuzzy number could be determined by Eq. (9).

$$
\begin{aligned}
& V\left(S \geq S_{1}, S_{2}, \ldots, S_{n}\right)=\min V\left(S_{i} \geq S_{k}\right), \\
& (k=1,2, \ldots, n ; k \neq i)
\end{aligned}
$$

$$
\text { If } d^{\prime}\left(A_{i}\right)=\min V\left(S_{i} \geq S_{k}\right),(k=1,2,3, \ldots, n ; k \neq i),
$$
then the normalized vector weight could be given as Eq. (10).

$$
w=\left(d\left(A_{1}\right), d\left(A_{2}\right), \ldots, d\left(A_{n}\right)\right)
$$

\subsection{The Fuzzy Compromise Ranking Method}

Compromise ranking method is an MCDM method developed by Opricovic [23] for the purpose of solving the problems characterized by multiple-conflicting criteria.
The process of compromise ranking method is aimed at finding a compromise solution as a solution nearest to the ideal solution. In order to provide precise results in uncertain environments, as is the multi-criteria optimization process, fuzzy logic is implemented within the compromise ranking process.

Let $\tilde{D}=\left[\tilde{f}_{i j}\right]_{m \times n}$ be the fuzzy aggregated decision matrix (11) of the considered problem with the $m$ alternative $\left(a_{1}, a_{2}, \ldots, a_{m}\right)$, and $n$ criteria $\left(c_{1}, c_{2}, \ldots, c_{n}\right)$.

$$
\begin{aligned}
& \begin{array}{llll}
c_{1} & c_{2} & \cdots & c_{n}
\end{array} \\
& \tilde{D}=\begin{array}{c}
a_{1} \\
a_{2} \\
\vdots \\
a_{m}
\end{array} \quad\left(\begin{array}{cccc}
\tilde{f}_{11} & \tilde{f}_{12} & \cdots & \tilde{f}_{1 n} \\
\tilde{f}_{21} & \tilde{f}_{22} & \cdots & \tilde{f}_{2 n} \\
\vdots & \vdots & \cdots & \vdots \\
\tilde{f}_{m 1} & \tilde{f}_{m 2} & \cdots & \tilde{f}_{m n}
\end{array}\right)
\end{aligned}
$$

where $\tilde{f}_{i j}$ the fuzzy rating of the aggregated alternative with respect to each criterion obtained by applying Eq. (12).

$\tilde{f}_{i j}=\frac{1}{k}\left[\tilde{f}_{i j 1} \oplus \tilde{f}_{i j 2} \oplus \ldots \oplus \tilde{f}_{i j k}\right]$

where $\tilde{f}_{i j s}$ is the fuzzy rating of the alternative established according to the $s^{\text {th }}$ expert's opinion $(s=1,2, \ldots, k)$.

The defuzzification of the fuzzy aggregated decision matrix (11) means the conversion of the fuzzy rating $\tilde{f}_{i j}=\left(f_{i j}^{l}, f_{i j}^{m}, f_{i j}^{u}\right)$ into the crisp values $f_{i j}$ by finding the Best Non-fuzzy Performance (BNP), which could be obtained by using the Center of Area (CA) established by Moeinzadeh and Hajfathaliha [25] given in (13).

$f_{i j}=\frac{\left(f_{i j}^{u}-f_{i j}^{l}\right)+\left(f_{i j}^{m}-f_{i j}^{l}\right)}{3}+f_{i j}^{l}$

It is further necessary to identify the best $\left(f_{i j}^{*}\right)$ and the worst $\left(f_{i j}^{-}\right)$values for all the considered criteria $(j=1, \ldots, n)$, which could be described as in Eqs. (14) and (15):

$f_{j}^{*}=\left\{\begin{array}{lll}\max _{i=1, \ldots, m} & f_{i j}, & j \in J \\ \min _{i=1, \ldots, m} & f_{i j}, & j \in J\end{array}\right.$

$f_{j}^{-}=\left\{\begin{array}{lll}\min _{i=1, \ldots, m} & f_{i j}, & j \in I \\ \max _{i=1, \ldots, m} & f_{i j}, & j \in J\end{array}\right.$

where $I$ refers to a set of the benefit-type criteria, and $J$ refers to a set of the cost-type criteria.

In order to obtain a compatible index ranking it is necessary to calculate the values $S_{i}(16), R_{i}(17)$ and $Q_{i}(18)$ for each alternative. 
The aggregated value of the $i^{\text {th }}$ alternative with a maximum group majority:

$S_{i}=\sum_{j=1}^{n} w_{j}\left(f_{j}^{*}-f_{i j}\right) /\left(f_{j}^{*}-f_{j}^{-}\right)$

The aggregated value of the $i^{\text {th }}$ alternative with a minimum individual regret:

$R_{i}=\max _{j=1, \ldots, n}\left[w_{j}\left(f_{j}^{*}-f_{i j}\right) /\left(f_{j}^{*}-f_{j}^{-}\right)\right]$

where $w_{j}(j=1,2, \ldots ., n)$ - fuzzy criteria weights for each criterion.

$Q_{i}=v \cdot \frac{S_{i}-S^{*}}{S^{-}-S^{*}}+(1-v) \frac{R_{i}-R^{*}}{R^{-}-R^{*}}$

where $S^{*}=\min _{i=1, \ldots, m} S_{i} ; S^{-}=\max _{i=1, \ldots, m} S_{i}$;

$R^{*}=\min _{i=1, \ldots, m} R_{i} ; R^{-}=\max _{i=1, \ldots, m} R_{i} ;$

The value $v$ can be defined as the weight of the decision-making strategy (which can be: $v>0,5$-voting by majority the rule; $v \approx 0,5$ - voting by a consensus; $v<0,5$ - voting with a veto).

The alternative obtained from $\max S_{i}$ shows the maximum group majority, whereas the alternative obtained from $\min R_{i}$ demonstrates the minimum individual regret of the alternative.

In order to obtain a compatible index ranking, it is necessary that the rank of the values $S_{i}, R_{i}$ and $Q_{i}$ should be established in descending order. The alternative with $\min Q_{i}\left(a^{1}\right)$ is adopted as the compromise solution if:

- $Q\left(a^{2}\right)-Q\left(a^{1}\right) \geq \frac{1}{m-1}$, where $a^{2}$ is the secondranked alternative according to the criterion of the minimization of $Q_{i} ; m$ is the total number of alternatives. Opricovic [24] refers to this condition as acceptable advantage, and

- $\quad a^{1}$ is also the alternative with $\min S_{i}$ and/or $\min R_{i}$ Opricovic [26] refers to this condition as acceptable stability in decision-making.

Otherwise,

- If $Q\left(a^{m}\right)-Q\left(a^{1}\right)<\frac{1}{m-1}$, then the compromise solution is a set of the alternative $\left(a_{1}, a_{2}, \ldots, a_{m}\right)$ with no comparative advantage of $a_{1}$ from the others;

- If the condition $a^{1}$ is alternative with max $S_{i}$ and/or $\max R_{i}$ is not met, then $a^{1}$ and $a^{2}$ have the same compromise solution, but there is no stability in decision-making.

\section{CASE STUDY}

The numerical example given in this section illustrates the real power transformers evaluation process carried out by utilizing the proposed methodology.
A team of four decision-makers with the academic and engineering backgrounds and the minimum of five years of experience was involved throughout the evaluation process. The team consists of the heads of the four departments, namely the Production, Maintenance, Procurement and Finance departments. These are the key departments directly involved in the equipment selection processes in the company the equipment is purchased for. This gives a concrete result by recording the previous experience of these experts and their awareness of the firm's goals. In addition, by their involvement throughout the evaluation process, the most important aspects of the evaluation are covered, thus providing a holistic approach.

The decision-makers were first introduced to the general decision-making objectives, after which they discussed the translation of those decision-making objectives into the criteria based on which an alternative would be evaluated. With the help of the existing literature and the decision-makers' own experience, potential evaluation criteria were proposed. The criteria generation procedure is inherently guided by the requirement that the number of evaluation criteria has to remain restricted so that the assessment remains feasible in terms of both data collection and data analysis. Once several rounds of discussions had been ended, a consensus was reached between the decision-makers, thus finalizing the list of the power transformer assessment criteria and forming the criteria base that would serve as a framework for the evaluation of alternatives.

A system of the five criteria for the evaluation of alternatives was then identified in accordance with the attitudes of the group of the experts involved in the decision-making process, after which the generated criteria were prioritized by using the fuzzy AHP method.

The generated criteria evaluation system includes the net present value, reliability, maintenance suitability, noload losses and a voltage drop. By integrating the selected criteria into the evaluation process, all the aspects of the considered problem significant for finding the optimal solution were included, thus enabling the base for a comprehensive evaluation process. The next phase refers to the evaluation and compromise ranking of alternatives by applying fuzzy compromise ranking method.

During the preliminary work, the decision-making team worked together to identify the potential alternatives suitable for the company's needs. After the initial screening, the decision-makers reached a consensus that the four alternatives with different performance, technical features and net present value of the investment funds necessary for their purchase and installation would remain for further evaluations, including:

$a_{1}$ - MINEL Power Distribution Liquid-filled Transformers - DkEo

$a_{2}$ - MINEL Power Distribution Liquid-filled Transformers with reduced losses - BkCo

$a_{3}-A B B$ Power Distribution Dry-type Transformers

$a_{4}-A B B$ Power Distribution Dry-type Transformers with reduced losses.

These alternative power transformers are of different performance and technical features, which were thoroughly explored and analyzed. 


\subsection{Criteria Prioritization by the Fuzzy AHP Method}

Step 1: In this step, the four experts with an academic and engineering background who were involved in the prioritization process expressed their perceptions of the preferences of the established criteria in relation to the others as linguistic statements. The experts used the linguistic variables for criteria weighting, as is shown in Tab. 1. These linguistic variables were further converted into the arithmetical form by representing them with fuzzy numbers (according to the fuzzified criteria evaluation scale given in Tab. 1), based on which the fuzzy pairwise comparison matrices were formed (Eq. (1)).

Tab. 2 represents aggregate pairwise comparison matrix formed by collecting opinions of experts involved in the criteria prioritization process Eq. (3).

Table 2 The aggregated fuzzy comparison matrix for the considered criteria

\begin{tabular}{|c|l|c|c|c|c|c|}
\hline \multicolumn{2}{|c|}{ Criterion } & $c_{1}$ & $c_{2}$ & $c_{3}$ & $c_{4}$ & $c_{5}$ \\
\hline$c_{1}$ & Net present value & $(1,1,1)$ & $(0.5,0.66,0.93)$ & $(0.42,0.58,0.84)$ & $(1.57,1.97,2.38)$ & $(1.28,1.68,2.07)$ \\
\hline$c_{2}$ & Reliability & $(1.07,1.52,2)$ & $(1,1,1)$ & $(1,1.32,1.68)$ & $(1.86,2.33,2.83)$ & $(1.63,1.99,2.36)$ \\
\hline$c_{3}$ & No-Load losses & $(1.19,1.73,2.38)$ & $(0.59,0.76,1)$ & $(1,1,1)$ & $(1.19,1.59,2)$ & $(1.19,1.59,2)$ \\
\hline$c_{4}$ & Maintenance suitability & $(0.42,0.51,0.64)$ & $(0.35,0.43,0.54)$ & $(0.5,0.63,0.84)$ & $(1,1,1)$ & $(1.19,1.73,2.38)$ \\
\hline$c_{5}$ & Voltage drop & $(0.48,0.6,0.78)$ & $(0.42,0.5,0.61)$ & $(0.93,1.24,1.68)$ & $(0.42,0.58,0.84)$ & $(1,1,1)$ \\
\hline
\end{tabular}

Step 2: Based on the aggregate fuzzy pairwise comparison matrix (Tab. 2), the fuzzy synthetic extent values $\left(S_{i}\right)$ for each of the criteria were calculated (4), (5), the results being listed in Tab. 3 .

Step 3: This step implies the construction of a possibilities matrix (Tab. 3) by the calculation of the minimum degree of the possibility of the superiority of each criterion over the others $\left(V\left(S_{2} \geq S_{1}\right)\right)$, according to (6)-(8). Based on the constructed possibilities matrix, the normalized weight vectors $(w)$ were obtained (10). The results are presented in Tab. 3.

Table 3 The synthetic extent values, the possibilities matrix, and criteria weight vectors

\begin{tabular}{|c|c|c|c|c|c|c|c|c|}
\hline \multirow{2}{*}{ Criterion } & \multirow{2}{*}{ Synthetic extent value } & \multicolumn{5}{|c|}{ Possibilities matrix } & \multirow{2}{*}{ Weight vector } & \multirow{2}{*}{$\begin{array}{l}\text { Normalized weight } \\
\text { vector }\end{array}$} \\
\hline & & $c_{1}$ & $c_{2}$ & $c_{3}$ & $c_{4}$ & $c_{5}$ & & \\
\hline Net present value & $(0.13 ; 0.2 ; 0.31)$ & - & 0.62 & 0.86 & 1 & 1 & 0.617 & 0.219 \\
\hline Reliability & $(0.18 ; 0.28 ; 0.43)$ & 1 & - & 1 & 1 & 1 & 1 & 0.354 \\
\hline No-Load losses & $(0.14 ; 0.23 ; 0.36)$ & 1 & 0.78 & - & 1 & 1 & 0.776 & 0.275 \\
\hline Maintenance suitability & $(0.1 ; 0.15 ; 0.23)$ & 0.65 & 0.27 & 0.52 & - & 1 & 0.268 & 0.095 \\
\hline Voltage drop & $(0.09 ; 0.14 ; 0.21)$ & 0.54 & 0.16 & 0.41 & 0.9 & - & 0.161 & 0.057 \\
\hline
\end{tabular}

According to the obtained results, the rank of the priority of one criterion over another is as follows: Reliability, No-Load losses, Net present value, Maintenance suitability and Voltage drop, with the relative weight coefficients: $0.354 ; 0.275 ; 0.219 ; 0.095$ and 0.057 , respectively. The obtained results indicate that the criterion Reliability has the most significant influence on the selection of the distribution transformers. The group of the significantly influential criteria also includes the Net present value and No-Load losses criteria, whereas the Maintenance suitability and Voltage drop criteria demonstrate a lesser impact on the ultimate decision. The result obtained in this phase will further be incorporated in the process of the evaluation of the alternative in the next phase.

\subsection{Compromise Alternative Ranking under Fuzzy Environment}

Step 1: Four experts were involved in the evaluation process. Each of them expressed the ratings for each alternative based on his/her own perceptions. They used the linguistic ratings (from Tab. 4) in order to rate the considered alternative.

Table 4 The fuzzified alternative evaluation scale

\begin{tabular}{|c|c|}
\hline Linguistic statements & Corresponding fuzzy number \\
\hline Very poor & $(0 ; 0 ; 1)$ \\
\hline Poor & $(0 ; 1 ; 3)$ \\
\hline Medium poor & $(1 ; 3 ; 5)$ \\
\hline Fair & $(3 ; 5 ; 7)$ \\
\hline Medium good & $(5 ; 7 ; 9)$ \\
\hline Good & $(7 ; 9 ; 10)$ \\
\hline Very good & $(9 ; 10 ; 10)$ \\
\hline
\end{tabular}

In order to successfully deal with the imprecise or vague nature of the linguistic assessments, they were translated into the corresponding TFNs according to the fuzzified evaluation scale shown in Tab. 4. According to these assessments, the individual fuzzy evaluated matrices for each expert were constructed.

These matrices were aggregated by using Eq. (12). The fuzzy aggregated evaluation matrix is shown in Tab. 5 .

Step 2: The fuzzy aggregated decision matrix (Tab. 5) was defuzzified by finding the BNP for each fuzzy rating ( $\left.\tilde{f}_{i j}\right)$ (13). The crisp values of the aggregated evaluation matrix are shown in Tab. 6.

Table 5 The fuzzy aggregated evaluation matrix

\begin{tabular}{|c|c|c|c|c|c|}
\hline \multirow{2}{*}{ Criteria } & \multirow{2}{*}{ Criteria Relative Weight } & \multicolumn{4}{|c|}{ Alternative } \\
\hline & & $a_{1}$ & $a_{2}$ & $a_{3}$ & $a_{4}$ \\
\hline Net present value & 0.219 & $(7 ; 9 ; 10)$ & $(6 ; 8 ; 9.5)$ & $(3.5 ; 5.5 ; 7,5)$ & $(2 ; 4 ; 6)$ \\
\hline Reliability & 0.354 & $(6 ; 8 ; 9,5)$ & $(5 ; 7 ; 9)$ & $(7.5 ; 9.25 ; 10)$ & $(9 ; 10 ; 10)$ \\
\hline No-load losses & 0.275 & $(0 ; 1 ; 3)$ & $(2.5 ; 4.5 ; 6.5)$ & $(0.75 ; 2.5 ; 4.5)$ & $(1.5 ; 3.5 ; 5.5)$ \\
\hline Maintenance suitability & 0.095 & $(4,5 ; 6,5 ; 8,25)$ & $(4.5 ; 6.5 ; 8.25)$ & $(8 ; 9.5 ; 10)$ & $(8 ; 9,5 ; 10)$ \\
\hline Voltage drop & 0.057 & $(5 ; 7 ; 9)$ & $(7 ; 9 ; 10)$ & $(3.5 ; 5.5 ; 7.5)$ & $(5 ; 7 ; 8.5)$ \\
\hline
\end{tabular}


Table 6 The crisp values for the aggregated evaluation matrix

\begin{tabular}{|l|c|c|c|c|}
\hline \multirow{2}{*}{\multicolumn{1}{|c|}{ Criteria }} & \multicolumn{4}{c|}{ Alternative } \\
\cline { 2 - 5 } & $a_{1}$ & $a_{2}$ & $a_{3}$ & $a_{4}$ \\
\hline Net present value & 8,67 & 7,83 & 5,5 & 4 \\
\hline Reliability & 7,83 & 7 & 8,92 & 9,67 \\
\hline No-load losses & 1,33 & 4,5 & 2,58 & 3,5 \\
\hline Maintenance suitability & 6,42 & 6,42 & 9,17 & 9,17 \\
\hline Voltage drop & 7 & 8,67 & 5,5 & 6,83 \\
\hline
\end{tabular}

Step 3: The best $\left(f_{j}^{*}\right)$ and the worst $\left(f_{j}^{-}\right)$values for all the considered criteria $(j=1, \ldots, n)$ were identified as described in (14), (15). Those values are presented in Tab. 7.

Table 7 The list of the best and the worst values of all criteria

\begin{tabular}{|c|c|c|}
\hline Alternative & $f_{j}^{*}$ & $f_{j}^{-}$ \\
\hline$a_{1}$ & 8.667 & 4 \\
\hline$a_{2}$ & 9.667 & 7 \\
\hline$a_{3}$ & 4.5 & 1.333 \\
\hline$a_{4}$ & 9.167 & 6.417 \\
\hline
\end{tabular}

Step 4: The values $S_{i}, R_{i}$ and $Q_{i}$ were calculated by using the relations (16), (17) and (18), respectively. As the $v$, the value 0.9 was used, which indicates that the decisionmaking strategy is the voting by the majority rule strategy. The results are accounted for in the Tab. 8.

Table 8 The values of $S_{i}, R_{i}$ and $Q_{i}$ for each alternative

\begin{tabular}{|c|c|c|c|}
\hline Alternative & $R_{i}$ & $S_{i}$ & $Q_{i}$ \\
\hline$a_{1}$ & 0,275 & 0,643 & 0,958 \\
\hline$a_{2}$ & 0,354 & 0,488 & 0,541 \\
\hline$a_{3}$ & 0,166 & 0,472 & 0,392 \\
\hline$a_{4}$ & 0,219 & 0,339 & 0,028 \\
\hline
\end{tabular}

Step 5: The ranking of the alternative was performed on the basis of the values $S_{i}, R_{i}$ and $Q_{i}$ (Tab. 9).

Table 9 The ranking of the alternative
\begin{tabular}{|c|c|c|c|c|}
\hline & \multicolumn{5}{|c|}{ Ranking alternative } \\
\cline { 2 - 5 } & 1 & 2 & 3 & 4 \\
\hline By $R_{i}$ & $a_{3}$ & $a_{4}$ & $a_{1}$ & $a_{2}$ \\
\hline By $S_{i}$ & $a_{4}$ & $a_{3}$ & $a_{2}$ & $a_{1}$ \\
\hline By $Q_{i}$ & $a_{4}$ & $a_{3}$ & $a_{2}$ & $a_{1}$ \\
\hline
\end{tabular}

The obtained results indicate that the alternative $a_{4}$ ABB Power Distribution Dry-type Transformers with reduced losses is the best-ranked alternative according to the criterion of the minimization of the $Q_{i}$ and $S_{i}$, and that the alternative $a_{4}$ is the second-ranked according to the measure of $R_{i}$, whereas the best-ranked alternative according to this criterion is the alternative $a_{3}-A B B$ Power Distribution Dry-type Transformers. Alternative $a_{4}-A B B$ Power Distribution Dry-type Transformers with reduced losses is adopted as a compromise solution since it is the best-ranked alternative according to the measure of $\min Q_{i}$, and is also the alternative with the acceptable advantage since the condition $Q\left(a^{2}\right)-Q\left(a^{1}\right) \geq \frac{1}{m-1}$ is met. The adopted compromise solution is stable within the decisionmaking process since the $a_{4}$ is the alternative with $\max S_{i}$ and/or $\min R_{i}$.

\section{CONCLUSION}

In the paper, the hybrid multi-criteria group decisionmaking model based on the fuzzy AHP and the fuzzy compromise ranking methods is presented. The model is aimed at providing an effective support to the process of the multi-aspect evaluation of the power transformers based on the consolidation of the opinions of a group of experts. The theoretical postulates of the paper and the numerical example point to the efficiency of the proposed model, as well as its ability to provide rational results. Namely, the AHP enables a reliable assessment of criteria weights, whereas the compromise ranking method provides the compromise ranking of the alternative based on the particular measure of closeness to the ideal solution. The fuzzy set theory was incorporated within the proposed model due to its ability to transfer decision-makers' ambiguous judgments expressed as linguistics statements to objective numerical data.

The obtained results point to the compromise solution with acceptable advantage and decision-making suitability; in other words, they point to the transformers with the most powerful performance in terms of the reliability level, the net present value of the investment funds necessary for their purchase and installation, no-load losses, maintenance suitability and the voltage drop. Also, the proposed model reduces subjectivism and generates much more rational solutions based on a reliable assessment of criteria weights, thus overcoming the problem of the ambiguities of human thinking, a multi-criteria evaluation and the compromise ranking of the considered alternative, and securing an effective support to group decision-making as well.

The main limitations of the proposed approach refer to the fact that it does not adequately take into account the nonlinear relationships that exist between the considered criteria. Therefore, further research aimed at problem improvement may be focused on the development of the approach that will enable interpretation of complex nonlinear relationships among considered criteria, such as approaches based on Analytic Network Process (ANP) methodology.

\section{Acknowledgements}

This study was supported by the Ministry of Education, Science and Technological Development of the Republic of Serbia, and these results are parts of Grant No. 451-03-9/2021-14/200132 with University of Kragujevac Faculty of Technical Sciences Čačak.

\section{REFERENCES}

[1] Bigdeli, M., Vakilian, M., \& Rahimpour, E. (2011). A new method for detection and evaluation of winding mechanical faults in transformer through transfer function measurements. Advances in Electrical and Computer Engineering, 11(2), 23-30. https://doi.org/10.4316/AECE.2011.02004

[2] Koochaki, A., Kouhsari, S. M., \& Ghanavati, G. (2008). Transformer internal faults simulation. Advances in Electrical and Computer Engineering, 8(2), 23-28. https://doi.org/10.4316/AECE.2008.02004

[3] Chakraborty, S. \& Banik, D. (2006). Design of a material handling equipment selection model using analytic hierarchy process. The International Journal of Advanced Manufacturing Technology, 28(11-12), 1237-1245. https://doi.org/10.1007/s00170-004-2467-y 
[4] Hodgett, R. E. (2016). Comparison of multi-criteria decision-making methods for equipment selection. The International Journal of Advanced Manufacturing Technology, 85(5-8), 1145-1157. https://doi.org/10.1007/s00170-015-7993-2

[5] Y1lmaz Kaya, B. \& Dağdeviren, M. (2016). Selecting occupational safety equipment by MCDM approach considering universal design principles. Human Factors and Ergonomics in Manufacturing \& Service Industries, 26(2), 224-242. https://doi.org/10.1002/hfm.20625

[6] Ghorabaee, M. K., Amiri, M., Zavadskas, E. K., \& Antucheviciene, J. (2018). A new hybrid fuzzy MCDM approach for evaluation of construction equipment with sustainability considerations. Archives of Civil and Mechanical Engineering, 18(1), 32-49. https://doi.org/10.1016/j.acme.2017.04.011

[7] Yilmaz, B. \& Dağdeviren, M. (2011). A combined approach for equipment selection: F-PROMETHEE method and zeroone goal programming. Expert Systems with Applications, 38(9), 11641-11650. https://doi.org/10.1016/j.eswa.2011.03.043

[8] Hadi-Vencheh, A. \& Mohamadghasemi, A. (2015). A new hybrid fuzzy multi-criteria decision making model for solving the material handling equipment selection problem. International Journal of Computer Integrated Manufacturing, 28(5), 534-550. https://doi.org/10.1080/0951192X.2014.880948

[9] Yazdani-Chamzini, A. (2014). An integrated fuzzy multi criteria group decision making model for handling equipment selection. Journal of Civil Engineering and Management, 20(5), 660-673. https://doi.org/10.3846/13923730.2013.802714

[10] Venkateswarlu, P. \& Sarma, B. D. (2016). Selection of supplier by using SAW and VIKOR methods. Journal of Engineering Research and Application, 6(11), 61-68.

[11] Yu, X., Zhang, H., Bouras, A., Ouzrout, Y., \& Sekhari, A. (2018). Multi-criteria decision making for PLM maturity analysis based on an integrated fuzzy AHP and VIKOR methodology. Journal of Advanced Manufacturing Systems, 17(02), 155-179. https://doi.org/10.1142/S0219686718500105

[12] Awasthi, A., Govindan, K., \& Gold, S. (2018). Multi-tier sustainable global supplier selection using a fuzzy AHPVIKOR based approach. International Journal of Production Economics, 195, 106-117. https://doi.org/10.1016/j.ijpe.2017.10.013

[13] Khamas, W. M., Naji,H. I., \& Hasan A. A. (2016) Evaluation and selection of urban planning projects using integration of methods fuzzy AHP and fuzzy VIKOR. International Journal of Soft Computing, 11(4), 227-235. https://doi.org/10.3923/ijscomp.2016.227.235

[14] Singh, S., Olugu, E. U., Musa, S. N., Mahat, A. B., \& Wong, K. Y. (2016). Strategy selection for sustainable manufacturing with integrated AHP-VIKOR method under interval-valued fuzzy environment. The International Journal of Advanced Manufacturing Technology, 84(1-4), 547-563. https://doi.org/10.1007/s00170-015-7553-9

[15] Fu, H. P., Chu, K. K., Chao, P., Lee, H. H., \& Liao, Y. C. (2011). Using fuzzy AHP and VIKOR for benchmarking analysis in the hotel industry. The Service Industries Journal, 31(14), 2373-2389. https://doi.org/10.1080/02642069.2010.503874

[16] Gul, M. (2018). Application of Pythagorean fuzzy AHP and VIKOR methods in occupational health and safety risk assessment: the case of a gun and rifle barrel external surface oxidation and colouring unit. International Journal of Occupational Safety and Ergonomics, 1-14. https://doi.org/10.1080/10803548.2018.1492251

[17] Jamali, N. \& Khamene, M. M. (2016).Using a fuzzy AHPVIKOR and BSC approach for evaluating aircraft maintenance unit performance. International Journal of Management, Accounting and Economics, 3(10), 623-634.

[18] Saaty, T. L. (1980). The analytic process: planning, priority setting, resources allocation. New York: McGrawL.

[19] Yu, J., Yao, J., \& Chen, Y. (2019). Credit scoring with AHP and fuzzy comprehensive evaluation based on behavioural data from Weibo platform. Tehnički Vjesnik/Technical Gazette, 26(2), 462-470. https://doi.org/10.17559/TV-20181217180231

[20] Puzovic, S., VesicVasovic, J., Radojicic, M., \& Paunovic V. (2019). An integrated MCDM approach to PLM software selection. Acta Polytechnica Hungarica, 16(4), 45-65. https://doi.org/10.12700/APH.16.4.2019.4.3

[21] Kramar, U. \& Topolšek, D. (2018). Applications of fuzzy Analytic Hierarchy Process in urban mobility system. Tehnički vjesnik/Technical Gazette, 25(5), 15531560. https://doi.org/10.17559/TV-20160927163837

[22] Zadeh, L. A. (1965). Fuzzy sets. Information and Control, 8(3), 338-353. https://doi.org/10.1016/S0019-9958(65)90241-X

[23] Chang, D. Y. (1992).Extent analysis and synthetic decision. Optimization Techniques and Applications, 1(1), 352-355.

[24] Opricovic, S. (1998). Multicriteria optimization of civil engineering systems, Faculty of Civil Engineering, Belgrade, 2-21.

[25] Moeinzadeh, P. \& Hajfathaliha, A. (2010).A combined fuzzy decision making approach to supply chain risk assessment. International Journal of Human and Social Sciences, 5(13), 859-875.

[26] Opricovic, S. \& Tzeng, G. H. (2004).Compromise solution by MCDM methods: A comparative analysis of VIKOR and TOPSIS. European Journal of Operational Research, 156(2), 445-455. https://doi.org/10.1016/S0377-2217(03)0002

\section{Contact information:}

Stojan VASOVIĆ, M.Sc

Distribution System Operator EPS Distribution, Belgrade, Serbia,

Čačak, 32000, Republic of Serbia

E-mail: stojan.vasovic@ods.rs

Aleksandar DRAGAŠEVIĆ, PhD

University of Kragujevac, Faculty of Technical Sciences Čačak,

Sveti Sava St, 65, Cačak 32000, Republic of Serbia

E-mail: aleksandar.dragasevic@ftn.kg.ac.rs

Slaviša PUZOVIĆ, M.Sc

Distribution System Operator EPS Distribution, Belgrade, Serbia

Prijepolje, 31300, Republic of Serbia

E-mail: slavisa.puzovic@ods.rs

Sanja PUZOVIĆ, M.Sc

(Corresponding author)

University of Kragujevac, Faculty of Technical Sciences Čačak,

Sveti Sava St, 65, Čačak 32000, Republic of Serbia

E-mail: sanja.puzovic@ftn.kg.ac.rs

Vladan PAUNOVIĆ, M.Sc

University of Kragujevac, Faculty of Technical Sciences Čačak,

Sveti Sava St, 65, Čačak 32000, Republic of Serbia

E-mail: vladan.paunovic@ftn.kg.ac.rs 